\title{
Integrating soft skills development into English language class
}

\author{
Svetlana Andrievskikh, Valentina Lapina* \\ Ural State University of Economics, 8 Marta Street, 62, 620144 Ekaterinburg, Russia
}

\begin{abstract}
Many employers around the world express their concerns about recent graduates' lack of necessary soft skills. They claim that new hires are inadequately prepared for handling some of the common challenges which have to be addressed at the workplace and the skills gap is widening with every passing year. Employers are looking for candidates who can understand and analyse ideas, tackle complex issues, actively contribute and take responsibility when working on projects, and are willing to develop their skills and acquire the new ones throughout their careers. Being aware of the problem, the authors undertook a study and propose some suggestions of integrating soft skills development into university English Language class.
\end{abstract}

\section{Introduction}

The turmoil of the XXI century and the growing impact of technology have changed our routines making us find new ways of leading, organising, working, learning, performing and fulfilling our everyday needs. When the whole world is adapting to the new normal, the labour market is extremely tight, which means soft skills such as problem solving, critical thinking, and innovation are more important than ever for recent university graduates. Soft skills development has been considered crucial for a number of years with companies paying great attention to carefully choosing candidates possessing the necessary soft skills to compete and thrive in the new environment. The market is developing very dynamically, new jobs, which we even could not think of yesterday, appear every day. Getting into university today, matriculants cannot be absolutely sure that their future profession will still exist when they graduate. So the challenge faced by education institutions today is not only to provide students with strong professional skills but help them master soft skills as well. This situation is universal, and Russia being interwoven into the world education system through Bologna process is not an exception in this context.

In 2018 HeadHunter and Microsoft conducted a study of the Russian labour market. The extensive examination of 11.6 million vacancies and 21.4 million CVs resulted in identifying several important soft skills, like critical thinking, complex problem solving, collaboration, emotional intelligence, and creativity.[1] According to the study, the new recruits should demonstrate certain skills sets. For example, a marketing specialist should be creative, good at multitasking, critical thinking, analysing huge amounts of data, leadership, and

\footnotetext{
*Corresponding author: valentina_lapina@yahoo.co.uk
} 
communication. An analyst should prove cognitive flexibility, adaptability, attention to detail, presentation skills, and ability to work in a team. And the higher the position is, the more crucial the soft skills are.

Sberbank Corporate University, which was established by the Sberbank group, the largest bank in Russia, focuses on providing learning opportunities for managers and company leaders. Currently, the Corporate University offers a Soft Revolution program that consists of six modules.

- Soft Revolution: how to be an engaging presenter?

- Soft Revolution: how to collaborate with business partners?

- Soft Revolution: how to be a great team player?

- Soft Revolution: how to master complex problem solving?

- Soft Revolution: how to deal with large amounts of data?

- Soft Revolution: how to manage time successfully?

The findings from McKinsey Global Survey on future workforce conducted in 2020 reveal that some organizations will face skill gaps within the next five years, while others report existing skill gaps. [2]

"Employers cannot solve the skills gap issue alone; they need support from education systems to build talent pools with skills relevant to today's business needs". [3] The Skills Gap 2019 Therefore "It's really important for companies to tell academia ... what they are looking for." [4] Bloomberg As a result, The Atlas of Emerging Jobs has been adopted by a great numbers of higher education institutions. The Atlas was developed by the Agency for Strategic Initiatives (ASI) in collaboration with Skolkovo Business School and gives a detailed description of employment trends, new professions and soft skills of the future. [5]

According to Marina Gorbis, "the soft skills are the most important and the toughest to master". [4]Bloomberg and that is why it is important to start planning for the future and developing soft skills as early as possible. In our opinion, a foreign language class is a perfect ground to master soft skills as students are able to learn from their peers, are not afraid of making mistakes and a foreign language course takes the whole two years to complete, which means that our work can be continuous, persistent and purposeful.

\section{Methodology}

The methodology for our study consisted of descriptive research design and a survey which comprised of a questionnaire, interviews, group discussions and observations.

\section{Research findings and suggestions}

Our research involved 70 first - and second - year students of Ural State University of Economics. Prior to distributing our questionnaire we asked our respondents if they were aware of the term "soft skills", what skills they considered important for their future careers, what skills they would like to develop and what kind of activities and university subjects helped students build up the necessary skills. Only 10 students out of 70 (about $15 \%$ ) were confident about the term; the others had never heard of it $(70 \%)$ or were not sure if they understood it correctly $(15 \%)$.

That is why we provided students with a list of the most important soft skills, and then we had small group discussions, so the students were given the opportunity to learn more about soft skills before filling in our detailed questionnaire.

The findings were a bit confusing. Only 43 percent of the respondents thought that university education promotes soft skills build-up, 36 percent expressed doubts and 21 percent gave a negative answer. Most students (65\%) supposed they were able to develop 
soft skills by themselves, pursuing their hobbies, participating in university extra-curricular activities, or taking different courses outside university, doing sport (14\%) or working (29\%).

Skill areas considered most important by our students are communication skills, including making presentations, effective listening, good speaking and writing skills (74\%); people skills, including team work and handling conflicts $(64 \%)$; organizational skills, including time management and effective planning (58\%). Only 14\% mentioned self-management skills such as self-motivation, ability to learn, make decisions and solve problems; and $11 \%$ emphasized IT skills.

The majority of respondents would like to improve their communication skills $(60 \%)$, flexibility, i.e. the ability to deal with challenges, new plans and ideas (57\%), organizational skills $(50 \%)$.

Analysing the questionnaires we were obviously greatly surprised by the fact that 21 percent of the students did not think that they could improve their soft skills during university classes, although we should take into account students' unawareness of the term and their lack of comprehension that soft skills development is an integral part of the university learning process.

It is worth mentioning that 60 percent consider their English classes a good opportunity to evolve their soft skills, and we, teachers of foreign languages, fully agree that soft skills development is an important part of foreign language classes and our aim is to contribute to increasing our students' employability.

Let us consider the ways we can integrate soft skills development into our classes. Aligning soft skills development with foreign language classes requires understanding of the skills first. For example, critical thinking which is considered one of the key skills needed at the workplace helps develop rational thought, and makes students examine and explain their reasoning for using this or that argument or doing something in a particular way.

In Cambridge Life Competencies Framework Critical thinking is divided into three areas:

- "Understanding and analysing links between ideas",

- "Evaluating ideas, arguments and options",

- "Synthesising ideas and information". [6]

Regarding the English language classes, while doing reading tasks, we can help our students improve their critical thinking skills by asking them to list key ideas in texts, compare opposite views, identify unconvincing arguments, select weighty arguments, and offer their reasoning. By doing that, we add perspective to reading tasks and encourage our students to reflect on how critically they complete reading tasks. We teach our students to understand topics, main ideas and supporting details, skim and scan, guess the meaning of words, work with the dictionary. They should be able to separate facts and opinions as " In this digital age we are surrounded by texts full of so-called facts but which do not necessarily come from guaranteed sources" [7]. Then, students should be able to find additional information to prove or debunk ideas and beliefs, answer questions, make plans and write abstracts. All these skills will be of great use in many jobs.

Moreover, we can successfully apply critical thinking development to writing tasks if we ask our students to think long and hard and observe carefully. We focus on helping our students learn how to convey their ideas and information in writing. One of the writing tasks we offer our students to complete is writing a book review. The objective of this task is to encourage students to think critically about the book. We usually extend the writing task into a group debate with plenty of "why" questions.

We believe it is very important to engage students into various debates as these require evaluation, address complex issues and motivate students to judge their counterpart's arguments and design solutions. Participating in debates, our students get the opportunity to practise communication skills, active listening skills, and presentation skills. Active listening skills are essential for debates, thus we motivate students to listen carefully to their 
counterparts, making sure they understand their counterparts and do not make any assumptions. We encourage our students to clarify by asking detailed questions or, when necessary, reword the message to check the understanding of the key points and demonstrate active engagement.

We also use debates to enhance teamwork and collaboration. According to Collaboration Guide for Teachers and Educational Managers, collaboration involves four main areas

- "Taking personal responsibility for own contribution to a group task",

- "Listening respectfully and responding constructively to others' contributions",

- "Managing the sharing of tasks in a project",

- "Working towards a resolution related to a task" [8].

Naturally, when getting ready to debate and while debating, students are involved in active collaboration, they take turns to speak and explain their points in detail, they encourage other students to contribute their ideas, opinions and comments, offer points to develop the discussion, and after the debate they do their best to provide helpful feedback.

We are aware of the fact that every person has their own opinion, skills and different level of knowledge. So the ability to work with others efficiently, wasting less time and efforts, is considered crucial today. Students must be able to work together supporting each other, while looking for solutions to solve problems. Collaboration provides students with vital interpersonal skills that prove to be very important at the workplace.

To equip our students with collaborative skills, we involve them into project work, providing them with extensive support, step-by step guides and practical tips at the early stage. As students have to collaborate with others to plan their work, so they hold a planning meeting first, share the tasks and assign roles, and they work out a schedule. Then, they research necessary information. During their work on the project, the students practise to ask other group members for help and offer help, so we encourage them after completion of their share to give their work to their partners to check. When the final product is presented, the students are given evaluation sheets to make notes of interesting things in presentations and check if all the necessary information is included in the presentation, if everything is clear and easy to follow. By evaluating their efforts and the efforts of their groupmates, they obtain practical, transferable skills.

To illustrate our project work activities, let us give you an example. First, we teach our students the structure and the language of a presentation, watch examples of effective presentations and those that went wrong, analyse the reasons of their success or failure, suggest better strategies. Then, we ask our students to make presentations of startup companies. Our students work in small teams of 3 or 4 and produce their presentations. Students pay a lot of attention to structuring and organizing their speech, as they realise that a good presenter must be a good speaker, who can both keep the audience interested, and achieve the result they need. "The usage of project method is directed at time-management skills and skills of planning and performing public speeches" [9].

As "lifelong learning has been identified as a means of sustaining employability as well as professional and career growth" we usually emphasize the importance of continuous learning. [10]Developing soft skills With technological advances and regular changes being introduced in the labour market, our students have to be well-prepared to acquire new skills and knowledge throughout their working lives. Thus, we draw our students' attention to learning to learn skill.

According to Learning to Learn Guide for Teachers and Educational Managers, there are three main areas of focus:

- "Practical skills for participating in learning",

- "Taking control of own learning",

- "Reflecting on and evaluating own learning success" [11]. 
It is evident, that learning to learn competency develops students' autonomy, thus, teachers of the foreign languages should plan activities to provide their students with opportunities to develop their learning to learn skill. The initial stage of learning to learn skill development can include the reflective and evaluative skills build-up to monitor students' progress. Teachers of the foreign languages can support by providing self-feedback forms for students to evaluate their performance. As university students are expected to complete coursework as a part of their educational course, we provide our students with practical ideas that help them with planning and conducting their research. First, we discuss how to find sources of information that are reliable and academic, then, help students choose relevant facts and data, and, finally, provide guidance on writing.

\section{Conclusion}

For higher education institutions developing soft skills should become a priority, as they are the employability skills which many employers are looking for nowadays. Teachers of foreign languages should be encouraged to make skills development clear to students, they should explain the way the skills are to be developed and assessed during the course. Relevant teaching techniques should be applied to provide students with the opportunity to actively participate and ensure effective skills development. University graduates in management positions will inevitably need to assess reports or present strong arguments to persuade their audience, therefore, foreign language classes should provide future managers with extensive practice to make them successful and to help them advance in their careers.

\section{References}

1. HeadHunter, Microsoft. The Russian Labour Market survey (2018)

2. S. Agrawal, A. De Smet, P. Poplawski, A. Reich, Beyond hiring: How companies are reskilling to address talent gaps, McKinsey \& Company (2020)

3. T. Burner, L.Supinski, S. Zhu, S.Robinson, Cate Supinski, The global skills shortage Bridging the Talent Gap with Education, Training and Sourcing, Society for Human Resource Management (2019)

4. The Atlas of Emerging Jobs, the Agency for Strategic Initiatives, Moscow, (2015)

5. Building Tomorrow's Talent: Collaboration Can Close Emerging Skills Gap, The Bureau of National Affairs, Inc. (2018)

6. Cambridge Life Competencies Framework, Critical Thinking, Introductory Guide for Teachers and Educational Managers, Cambridge University Press (2019)

7. J. Hughes, Critical Thinking in the Language Classroom, ELI Publishing, (2014)

8. Cambridge Life Competencies Framework, Collaboration, Introductory Guide for Teachers and Educational Managers, Cambridge University Press (2019)

9. E.D.Platova, A. V. Pavlova, Soft skills development in teaching business interaction, 10th International Conference "Word, Utterance, Text: Cognitive, Pragmatic and Cultural Aspects", European Publisher (2020)

10. M. Wats, R. K.Wats, Developing Soft Skills in Students, The International Journal of Learning Annual Review, 15 (2009)

11. Cambridge Life Competencies Framework, Learning to Learn, Introductory Guide for Teachers and Educational Managers, Cambridge University Press (2019) 